\title{
Glycaemic index, Glycaemic load and dietary fibre characteristics of two commercially available fruit smoothies
}

Georgios Saltaouras ${ }^{1, *}$, Patricia K. Shaw ${ }^{1, *}$, Ann C. Fraser ${ }^{1}$, Chris Hawes ${ }^{2}$, Harry Smith ${ }^{2}$, Louisa Handley $^{3}$, Helen Whitby ${ }^{3}$, Sangeetha P. Thondre ${ }^{1}$, Helen J. Lightowler ${ }^{1}$

${ }^{1}$ Oxford Brookes Centre for Nutrition and Health, Department of Sport, Health Sciences and Social Work, Oxford Brookes University, Oxford, UK

${ }^{2}$ Plant Cell Biology, Department of Biological and Medical Sciences, Oxford Brookes University, Oxford, UK.

${ }^{3}$ Innocent drinks Ltd, Fruit Towers, 342 Ladbroke Grove, London, UK

Key words: Glycaemic Index, Glycaemic Load, mango and passion fruit smoothie, strawberry and banana smoothie, cellulose, pectin

\section{Correspondence:}

Georgios Saltaouras, Oxford Brookes Centre for Nutrition and Health, Department of Sport, Health Sciences and Social Work, Oxford Brookes University, Headington Campus, Gipsy Lane, OX3 0BP, Oxford, UK

Contact Information:

Tel: +44 1865 483283, Email: 16021065@brookes.ac.uk 


\begin{abstract}
In light of the updated Eatwell Guide and the corresponding change in the consumption of fruit smoothies, the aim of this study was to measure the glycaemic index and load of two commercial fruit smoothies and to investigate the retention of dietary fibre following production. In vitro analysis was performed to identify fibre material (cellulose and pectins) using calcofluor staining and immunocytochemical labelling. A repeated measures crossover study was conducted (n 10) to determine the Glycaemic Index (GI) and Glycaemic Load (GL) of the smoothies. Results showed that dietary fibre was still present in the smoothies after processing (16.9-17.5\% cellular material by dry weight). The GI was low for both smoothies (39 and 36), whereas the GL was medium and borderline-low, respectively (11.4 and 9.7). The retention of fibre in these smoothies may have a potential positive effect on glycaemic response and may contribute to daily fibre requirements.
\end{abstract}




\section{Introduction}

The Glycaemic Index (GI) is used to classify foods according to their effect on the postprandial blood glucose (BG) levels of an individual. The GI is expressed as the percentage of the incremental area under the BG curve (iAUC) of the test food compared to the iAUC of the reference food (Jenkins et al. 1981). Large epidemiological studies have observed a potential favourable effect of low GI diets in lipid management and diabetes through the reduction of postprandial glycaemia and protein markers related to glucose control in the short to intermediate term (Esfahani et al. 2009). The amount of carbohydrate eaten dictates the actual increase in BG levels (Franz et al. 2002), so the concept of glycaemic load (GL) was developed based on the GI value of the food and the amount eaten (Salmeron et al. 1997).

The GI of a food is influenced by nutrients such as protein and dietary fibre, as well as food processing and preparation methods (Vosloo 2005). The term 'dietary fibre' includes all plant parts that are indigestible in the human small intestine and are partly or completely fermented in the colon (DeVries 2003). Historically, dietary fibre is classified into soluble (pectins, gums, inulin-type fructans and some hemicelluloses) and insoluble (cellulose, some hemicelluloses and lignin) fibre (Lattimer and Haub 2010). Gastrointestinal function may be influenced by the presence of dietary fibre in numerous ways, including alterations in gastrointestinal transit time, increased digesta viscosity and cell wall encapsulation (Grundy et al. 2016). As a result, the presence of dietary fibre can contribute to a delayed rise in postprandial BG and insulin concentrations (Lattimer and Haub 2010).

Fruits are rich in dietary fibre, made up of mainly water-insoluble fibre and to a lesser extent water-soluble fibre on an average ratio 2:1 (Li et al. 2002; Slavin and Lloyd 2012). Smoothies 
contain both whole, homogenised fruit and fruit juice and therefore typically contain more dietary fibre than juice ( $1.7 \mathrm{~g}$ per $100 \mathrm{~g}$ vs. $0.1 \mathrm{~g}$ per $100 \mathrm{~g}$ respectively) (Ruxton 2008). Prior to 2016, a fruit smoothie that contained at least $150 \mathrm{ml}$ of fruit juice and $80 \mathrm{~g}$ of crushed fruit pulp could claim a maximum of two of the 5-a-day recommendation for fruit and vegetables. Following a report on dietary carbohydrates and their role in human health produced by the Scientific Advisory Committee on Nutrition (SACN) (Public Health England 2015), Public Health England launched the Eatwell Guide to reflect SACN's recommendations (Public Health England 2016). The Eatwell Guide now considers $150 \mathrm{ml}$ of a fruit smoothie as a maximum of one of the 5-a-day because of its composition of dietary carbohydrates (high in sugars and low in dietary fibre). SACN also recommended that the dietary reference value for dietary fibre for adults should be increased to 30 g/day (Public Health England 2015).

In light of the above, this study aimed to (i) perform an analysis of cell wall material in two commercially available fruit smoothies compared to constituent whole fruit and (ii) evaluate the glycaemic response and GI classification of these two fruit smoothies in healthy men and women.

\section{Methods}

\section{Section 1: Microscopical analysis of cell wall material in fruit smoothies.}

A microscopical investigation was undertaken to determine the retention of cellular material in two commercially available fruit smoothies ('Mango and Passion Fruit' and 'Strawberry and Banana'; Innocent Ltd.) and constituent raw fruit (banana, mango, passion fruit and strawberry; whole, blended, sieved and chewed). The smoothies were supplied by Innocent Ltd. and the raw 
fruit was bought from local markets. Whole fruits were cut into smaller sections (around $1 \mathrm{~cm}^{2}$ ). Blended fruit samples were placed into a 'Philips HR2096 Avance' Blender and blended using the 'smoothie' function for 1 minute. Sieved fruit samples (banana and mango only) were pressed through 0.8 and $2 \mathrm{~mm}$ sieves. Chewed fruit samples were prepared by chewing the fruit exactly 15 times before being expectorated. Fruit cell wall material was visualised using specific macromolecule labelling, fluorescence confocal microscopy and scanning electron microscopy.

\section{Calcofluor (optical brightner) staining for cellulose}

$4 \mu 1$ of $0.01 \%$ Calcofluor-white stain was applied to $500 \mu$ of each sample and samples were left to incubate at $4{ }^{\circ} \mathrm{C}$ for 20 minutes. Then, each sample was spread onto slides for an additional 15 minutes. Slides were imaged with a Zeiss LSM 510 META laser scanning confocal microscope.

\section{Immunocytochemical labelling of pectins}

The monoclonal antibody JIM 7 recognises methyl esterified pectins in plant cells walls and was chosen for immunofluorescence microscopy (Knox et al. 1990). Cells were fixed in $4 \%$ paraformaldehyde in 0.1M PIPES (piperazine-N,N'-bis(2-ethanesulfonic acid)) buffer for 30 minutes. After centrifugation and wash in 1x phosphate buffered saline (PBS) buffer, a blocking buffer consisting of $1 \%$ bovine serum albumin (BSA) in $0.1 \mathrm{M}$ PIPES buffer was applied to the sample and left to incubate to reduce non-specific binding of antibodies. JIM7 primary monoclonal IgA rat antibody was applied to the samples which were then incubated for 1 hour at room temperature. Alexa Fluor 488 (Invitrogen) rabbit anti-rat IgG secondary antibody was applied to the samples which were then incubated for 1 hour at room temperature. Cells were transferred and mounted on Vectorbond-coated slides in Citifluor antifade mountant before 
coverslips were applied. Samples were then imaged with a Zeiss LSM 510 META laser scanning confocal microscope.

Preparation for scanning electron microscopy

Scanning Electron Microscopy (SEM) was performed on smoothies and whole fruit only. Both smoothie samples and whole fruit were completely dehydrated before being mounted onto SEM stubs and 'sputter' coated with a layer of gold. All samples were imaged using a Hitachi S-3400 scanning electron microscope (Hitachi HiTec, UK) at $5 \mathrm{kV}$.

\section{Section 2: Glycaemic Index of fruit smoothies}

Study design

A repeated measures crossover design was used to evaluate the glycaemic response of the smoothies (Strawberry \& Banana and Mango \& Passion fruit) in comparison to reference glucose. The study was conducted at the Oxford Brookes Centre for Nutrition and Health, Oxford Brookes University (UK) according to Good Clinical Practice Guidelines. Ethical approval for the study was obtained from the University Research Ethics Committee (UREC) at Oxford Brookes University (UREC Registration No: 090392). Participants provided written informed consent.

\section{Participants}

Participants were recruited from staff and students at Oxford Brookes University. Participants were excluded from the study if they had a Body Mass Index (BMI) $\geq 30 \mathrm{~kg} / \mathrm{m}^{2}$; fasting BG $>6.1$ 
$\mathrm{mmol} / \mathrm{l}$; aged $<18$ or $>65$ years; pregnant or lactating; known food allergy or intolerance; diabetes mellitus or use of hyperglycaemic drugs, insulin, steroids, protease inhibitors or psychotics or medical conditions known to affect glucose regulation, appetite and/or digestion and absorption of nutrients.

\section{Anthropometrical measurements}

Height was measured to the nearest centimetre using a stadiometer (Seca Ltd, UK). Body mass and body fat percentage was measured using a body composition analyser (Tanita BC-418 MA; Tanita UK Ltd).

\section{Study products}

The two smoothies were provided by Innocent Ltd. and were compared to a reference food (glucose-monohydrate dissolved in water) in equivalent available carbohydrate amounts of 25 grams. The available carbohydrate and serving sizes are shown in Table 1.

[Table 1 near here]

\section{Test protocol and laboratory measurements}

The study was carried out in accordance with ISO standards (ISO/FDIS 26642:2010 Food products-Determination of the glycaemic index (GI) and recommendation for food classification (ISO 2010). The reference food was tested on three separate days and the smoothies were tested once each with at least a one-day gap between measurements to minimise carry-over effects. All tests took place before 10:00 am after a 12-hour overnight fast. BG measurements were taken by fingerpick using the Unistik ${ }^{3} 3$ single-use lancing device (Owen Mumford) and measured using the HemoCue Glucose 201+ analyser (HemoCue ${ }^{\circledR}$ Ltd). BG 
measurements were taken in duplicate at baseline $(-5$ and $0 \mathrm{~min})$ before consumption of the smoothies or reference food. Further blood measurements were taken at 15, 30, 45, 60, 90 and 120 min after starting to drink. Participants consumed the smoothies or reference food at a comfortable pace, within 15 minutes.

\section{Analysis}

Types of cells found in smoothies and fruit are presented in percentages (\%). Images were interpreted to identify the type and size of cells in smoothie and fruit samples. Cells were classified for convenience into three main categories: 1. Vascular: Long fibrous cells and xylem; 2. Parenchyma: Irregular or isodiametric cells forming packing tissue; 3. Other, unidentified cell types. Size was determined by length (longest axis of the cell) and width (axis perpendicular to that of the length). For cell size, a total of 10 cells were surveyed for each smoothie and fruit sample in order to generate a reliable average length and width for each. Results for cell type are presented as mean $\pm \mathrm{SD}$ for both length and width.

The iAUC was calculated geometrically in Microsoft Excel by applying the trapezoid rule ignoring the area beneath the baseline. If the coefficient of variance between the three iAUC values for the reference glucose is greater than $30 \%$, the mean of the two reference glucose values with a coefficient of variance less than 30\% should be used instead (Brouns et al. 2005). For the two smoothies, the GI value was taken as the mean for the whole group. In accordance with the ISO standards, participants who produced a GI value that fell outside the range of \pm 2 standard deviations from the mean were excluded (ISO 2010). 
For each subject, GL was calculated as the available carbohydrate content of the serving measured in grams (g) multiplied by the smoothie's GI, and divided by 100 . The serving of the smoothies was determined at the commercially sold volume of $250 \mathrm{ml}$ (one small bottle):

$$
\mathrm{GL}=(\text { Available carbohydrate content in } 250 \mathrm{ml} \text { smoothie * GI) / } 100
$$

\section{Results}

Section 1: Microscopical analysis of cell wall material in fruit smoothies.

\section{Cell types and size of fruits and smoothies}

The Mango and Passion Fruit and Strawberry and Banana smoothie samples contained a mean of $16.9 \%$ and $17.5 \%$ fruit cellular material respectively by dry weight (based on 10 specimens). Percentages of different cell types assessed from fluorescently labelled samples (Cacofluor for cellulose and immunofluorescence for methyl esterified pectins) for smoothies and fruit are presented in Figure 1. Parenchyma is the main cell type in all but passion fruit, which has the highest percentage of vascular cells. Smoothies' cell dimensions appeared greater than that from the fresh fruit (Table 2).

[Table 2 and Figure 1 near here]

Scanning Electron Microscopy of Fruit Smoothies

Scanning electron microscopy of cellular material from fruit smoothies revealed large aggregations of cells surviving the production process (Figure 2). Especially in the strawberry and banana smoothie, large aggregates of parenchymatous and vascular tissue were found (Figure 2A,B). 
[Figure 2 near here]

\section{Section 2: Glycaemic Index of Fruit Smoothies}

\section{Participants}

Twelve participants were recruited and completed all tests. Two participants produced a GI outside the range of \pm 2 standard deviations from the mean and were excluded. Thus, a total of five male and five female participants were included in the analysis. The subject characteristics are presented in Table 3.

[Table 3 near here]

Glycaemic Response, Glycaemic Index and Glycaemic Load

The mean (SEM) changes in BG from baseline in response to the reference glucose and the two smoothies are shown in Figure 3. The mean (SEM) GI and GL values of the two smoothies are shown in Table 4. Both smoothies had a low GI (less than 55). The GI of the reference glucose is 100. The commercially available serving size of $250 \mathrm{ml}$ 'Strawberry and Banana' smoothie had a medium GL, whereas that of the 'Mango and Passion Fruit' smoothie had a low GL.

[Table 4 and Figure 3 near here]

\section{Discussion}

The importance of fruit as a source of dietary fibre is well established (Slavin \& Lloyd 2012; Dahl \& Stewart 2015); however, few studies have evaluated the dietary fibre content of fruit smoothies and their subsequent effect on BG response (George et al. 2009). The results of this study indicate that the fibre present in the Strawberry and Banana and Mango and Passion Fruit 
smoothies may have a beneficial effect on BG. The Mango and Passion Fruit smoothie had a low GI and low GL and the Strawberry and Banana Smoothie had a low GI and a medium GL.

In addition to the strawberries and banana, the Strawberry and Banana smoothie also contains apple, orange, blackcurrants and white grapes. The Mango and Passion Fruit smoothie contains apple, mango, banana, orange, passionfruit, peach and lime. Whilst it is not possible from the present study to attribute the source or the quantity of the fibre, the results indicate that the Strawberry and Banana and Mango and Passion Fruit smoothies retain a considerable amount of fibre after processing, as demonstrated by the presence of whole cells. The cell wall integrity indicates that nutrients cannot be released from the food matrix and, therefore, may decrease the rate of nutrient digestion and postprandial glycaemic response (Grundy et al., 2016). Chu et al. (2017) found that cells in smoothies remain intact even after in vitro digestibility, which could be a mechanism behind lowering GI.

The Strawberry and Banana and Mango and Passion Fruit smoothies contain 1.5 and $3.3 \mathrm{~g}$ of fibre per $250 \mathrm{ml}$, respectively, as indicated on the nutritional information labels. Within the scope of our methodology, we have identified the presence of pectin and cellulose in the tested smoothies. Pectin appears to have an effect on postprandial BG due in part to the reduced rate of diffusion of available carbohydrates to the absorptive mucosal surface, resulting from the fibre's viscosity (European Food Safety Authority, 2010; Elleuch et al. 2011; McRorie and McKeown 2017). As the viscosity of the fibre increases there is an increase in the reduction of postprandial BG and insulin response (Jenkins et al. 1978). In addition, swelling and dissolution of soluble fibre may be influenced by the moisture of the food (Grundy et al. 2016). Therefore, it can be assumed that the viscosity of a highly hydrated food, such as a smoothie, would influence glycaemic response. Observational studies suggest an inverse relationship between soluble fibre 
consumption and Type 2 diabetes incidence (Meyer et al. 2000, Montonen et al. 2003). Cellulose may accelerate the secretion of glucose-dependent insulintropic polypeptide (GIP) and the production of short chain fatty acids, via fermentation in the bowel (Lattimer and Haub 2010). However, research on the role of natural cellulose in glycaemic response is limited and mixed results have been generated (Lattimer and Haub 2010).

The dietary fibre recommendation was revised in 2015 from $24 \mathrm{~g}$ per day to $30 \mathrm{~g}$ per day (as measured by the AOAC method) in light of stronger evidence that an increased dietary fibre intake is associated with a lower risk of cardiovascular disease, type 2 diabetes and colorectal cancer (SACN 2015). A significant amount of research has also demonstrated the beneficial effects of plant based polysaccharides on metabolic syndrome (Ahmadi et al. 2017). Current UK statistics show that average intake of dietary fibre in all age groups is low, with children and adults consuming $4 \mathrm{~g}$ and $12 \mathrm{~g}$ below the recommended intake values, respectively (Lockyer et al, 2016).

Furthermore, following the ISO GI test protocol (ISO 2010), the present study found that both the Strawberry and Banana and Mango and Passion Fruit smoothies had a low GI (39 \& 36 respectively). This is similar to the estimated GI of the whole fruit components, with the exception of the banana: mango (GI 51); banana (GI 47-70); strawberries (GI 40); apple (GI 2844) (Atkinson et al. 2008) and passion fruit (GI 16) (Passos et al. 2015). High dietary fibre in a food product has been shown to be related to the GI of that product (Wolever 1990; Marangoni \& Poli 2008; Björck \& Elmståhl 2003).

The smoothies assessed in this study contain naturally occurring sugars (fructose) derived exclusively from fruit. Recent research has found that the replacement of sucrose with fructose in 
foods and beverages reduced postprandial glycaemia (Rodrigues et al. 2018). In addition, a review has highlighted that fructose-containing sugars are not associated with cardiometabolic risk factors, when there is energy balance (Khan and Sievenpiper 2016). Epidemiological studies have shown that fruit juice consumption is associated with better diet quality (O’Neil et al. 2011) and higher intake of whole fruit and vegetables (Gibson 2012). Results of the National Dietary and Nutrition Survey (NDNS) for 2012/13-2013/14 highlight that adults are not achieving the recommended daily intake of at least five portions of fruit and vegetables per day, with only $27 \%$ of adults and 35\% of older adults meeting the 5-a-day (Public Health England \& Food Standards Agency 2016). In Scotland, the average intake was highest at only 3.3 portions of fruit and vegetables per day among those aged 55-64 years (The Scottish Government 2017). Consumption of $150 \mathrm{ml}$ of a smoothie can contribute to a maximum of one of the 5-a-day.

The main limitation of this study is that the in vitro analysis of the fibre material did not permit quantification or the distinction between soluble and insoluble fibre, but only indicated the presence of dietary fibre after fruit processing. However, the presence of intact cells postproduction might impede the digestibility of smoothies adding to the benefits related to the quantity and quality of fibre (Grundy et al., 2016).

\section{Conclusions}

In this study, we found that two commercial fruit smoothies retain aggregates of cells after processing. Commercially available smoothies may therefore offer a source of fibre and contribute to the intake of fruit and vegetables in the diet. In addition, the GI value was low for both smoothies. Our study provides further support for the inclusion of $150 \mathrm{ml}$ fruit smoothies as part of a healthy balanced diet. Further research is required to determine whether the positive 
benefits of fibre and other nutrients present in the fruit smoothies have an impact on minimizing the risk of obesity and associated metabolic health outcomes.

\section{Declaration of interest}

The study was funded by Innocent Ltd, London, UK. GS, PKS were, at the time this study was conducted, employees of the Oxford Brookes Centre for Nutrition and Health and HS was a research student at the Department of Biological \& Medical Sciences. Innocent Ltd has had no involvement in the analysis of the results. 


\section{References}

Ahmadi S, Mainali R, Nagpal R, Sheikh-Zeinoddin M, Soleimanian-Zad S, Wang S, Deep G, Mishra SK, Yadav H. 2017. Dietary polysaccharides in the amelioration of gut microbiome dysbiosis and metabolic diseases. Obes Control Ther 4:1-15.

Atkinson FS, Foster-Powell K, Brand-Miller JC. 2008. International Tables of Glycemic Index and Glycemic Load Values. Diabetes Care 31:2281-2283

Björck I, Elmståhl HL. 2003. The glycaemic index: importance of dietary fibre and other food properties. Proc Nutr Soc 62:201-6.

Brouns F, Bjorck I, Frayn KN, Gibbs AL, Lang V, Slama G, Wolever TMS. 2005. Glycaemic index methodology. Nutrition Research Reviews 18:145-171.

Chu J, Igbetar BD, Orfila C. 2017. Fibrous Cellular Structures are Found in a Commercial Fruit Smoothie and Remain Intact during Simulated Digestion J Nutr Food Sci 7:576

Dahl WJ and Stewart ML. 2015. Position of the Academy of Nutrition and Dietetics: Health Implications of Dietary Fiber. J Acad Nutr Diet. 115:1861-70.

DeVries JW. 2003. On defining dietary fibre. Proc Nutr Soc 62:37-43.

Elleuch M, Bedigian D, Roiseux O, Besbes S, Blecker C, Attia H. 2011. Dietary fibre and fibrerich by-products of food processing: Characterisation, technological functionality and commercial applications: A review. Food Chem. 124: 411-421.

European Food Safety Authority. 2010. Scientific Opinion on the substantiation of health claims related to pectins and reduction of post-prandial glycaemic responses (ID 786), maintenance of normal blood cholesterol concentrations (ID 818) and increase in satiety leading to a reduction in energy intake (ID 4692) pursuant to Article 13(1) of Regulation (EC) No 1924/2006. EFSA Journal 8:1747 
Food Products-Determination of the glycaemic index (GI) and recommendation for food classification. ISO 26642: 2010(E).

Franz MJ, Bantle JP, Beebe CA, Brunzell JD, Chiasson JL, Garg A, Holzmeister LA, Hoogwerf B, Mayer-Davis E, Mooradian AD, Purnell JQ, Wheeler M. 2002. Evidence-based nutrition principles and recommendations for the treatment and prevention of diabetes and related complications. Diabetes Care 25: 148-198.

George TW, Niwat C, Waroonphan S, Gordon MH, Lovegrove JA. 2009. Effects of chronic and acute consumption of fruit- and vegetable-puree-based drinks on vasodilation, risk factors for CVD and the response as a result of the eNOS G298T polymorphism. Proceedings of the Nutrition Society. 68:148-61.

Gibson S. 2012. Fruit juice consumption in the National Diet and Nutrition Survey (NDNS 2008-2010): associations with diet quality and indices of obesity and health. Proceedings of the Nutrition Society 71(OCE3).

Grundy MML, Edwards CH, Mackie AR, Gidley MJ, Butterworth PJ, Ellis PR. 2016. Reevaluation of the mechanisms of dietary fibre and implications for macronutrient bioaccessibility, digestion and postprandial metabolism British Journal of Nutrition, 116; $816-833$

Jenkins DJA, Wolever TMS, Leeds AR, Gassull MA, Haisman P, Dilawari J, Goff DV, Metz GL, Alberti KGMM. 1978. Dietary fibres, fibre analogues, and glucose tolerance: importance of viscosity. BMJ, 1:1392-1394.

Jenkins DJA, Wolever TMS, Taylor R, Barker H, Fielden H, Baldwin JM, Bowling AC, Newman HC, Jenkins AL, Goff DV. 1981. Glycemic index of foods: a physiological basis for carbohydrate exchange. Am J Clin Nutr 34:362-366. 
Khan TA and Sievenpiper JL. 2016. Controversies about sugars: results from systematic reviews and meta-analyses on obesity, cardiometabolic disease and diabetes. European Journal of Nutrition. 55 (Suppl 2):S25-S43

Knox JP, Linstead PJ, King J, Cooper C, Roberts K. 1990. Pectin esterification is spatially regulated both within cell walls and between developing tissues of root apices. Planta $181: 512-521$.

Lattimer JM, Haub MD. 2010. Effects of Dietary Fiber and Its Components on Metabolic Health. Nutrients 2:1266-1289

Li BW, Andrews KW, Pehrsson PR. 2002. Individual Sugars, Soluble, and Insoluble Dietary Fiber Contents of 70 High Consumption Foods. Journal of Food Composition and Analysis $15,715-723$

Lockyer S, Spiro A, Stanner S. Dietary fibre and the prevention of chronic disease - should health professionals be doing more to raise awareness? Nutrition Bulletin 41, $214-231$.

Marangoni F, Poli A. (2008). The glycemic index of bread and biscuits is markedly reduced by the addition of a proprietary fiber mixture to the ingredients. Nutr Metab Cardiovas 18, 602605.

McRorie JW and McKeown NM. 2017. Understanding the physics of functional fibers in the gastrointestinal tract: An evidence-based approach to resolving enduring misconceptions about insoluble and soluble Fiber. J Acad Nutr Diet 117:251-264.

Meyer KA, Kushi LH, Jacobs Jr DR, Slavin J, Sellers TA, Folsom AR. 2000. Carbohydrates, dietary fiber, and incident type 2 diabetes in older women. Am J Clin Nutr 71:921-30

Montonen J, Knekt P, Järvinen R, Aromaa A, Reunanen A. 2003 Whole-grain and fiber intake and the incidence of type 2 diabetes. Am J Clin Nutr 77:622-9. 
O’Neil CE, Nicklas TA, Zanovec M and Fulgoni, VL. 2011. Diet quality is positively associated with $100 \%$ fruit juice consumption in children and adults in the United States: NHANES 2003-2006. Nutrition Journal 10:17

Passos TU, Sampaio HAC, Sabry MOD, De Melo MLP, Coelho MAM, Lima JWO. 2015. Glycemic index and glycemic load of tropical fruits and the potential risk for chronic diseases. Food Sci Technol Campinas 35:66-73

Public Health England. 2015. Scientific Advisory Committee on Nutrition: Carbohydrates and $\begin{array}{llll}\text { Health. } & \text { Knited }\end{array}$ https://www.gov.uk/government/publications/sacn-carbohydrates-and-health-report

Public Health England. 2016. The Eatwell Guide. United Kingdom. Available from: https://www.gov.uk/government/publications/the-eatwell-guide

Public Health England and Food Standards Agency. 2016. National Diet and Nutrition Survey: Results from Years 5 and 6 (combined) of the Rolling Programme (2012/2013 - 2013/2014). Available from: https://assets.publishing.service.gov.uk/government/uploads/system/uploads/attachment_data/file/55 1352/NDNS_Y5 6_UK_Main_Text.pdf

Rodrigues N, Peng M, Oey I, Venn BJ. 2018. Glycaemic, uricaemic and blood pressure response to beverages with partial fructose replacement of sucrose. Eur J Clin Nutr [Epub ahead of print].

Ruxton CHS. 2008 Smoothies: one portion or two? British Nutrition Foundation Nutrition Bulletin, 33:129-132

Salmeron J, Manson JE, Stampfer MJ, Colditz GA, Wing AL, Willet WC. 1997. Dietary fiber, glycemic load, and risk of non-insulin-dependent diabetes mellitus in women. JAMA 227:472-477. 
The Scottish Government. 2017. Scottish Health Survey 2016: Volume 1: Main Report. Available from: http://www.gov.scot/Publications/2017/10/2970/345741

Slavin JL and Lloyd B. 2012. Health Benefits of Fruits and Vegetables. Adv Nutr 3:506-516

Wolever TMS. 1990. Relationship between dietary fiber content and compositionin foods and the glycemic index. Am J Clin Nutr 51:72-5.

Vosloo CM. 2005. Some factors affecting the digestion of glycaemic carbohydrates and the blood glucose response. JFECS 33. 


\section{Tables}

Table 1. Available carbohydrate and serving sizes of the reference food and smoothies.

\begin{tabular}{ccc}
\hline & $\begin{array}{c}\text { Available } \\
\text { carbohydrate }\end{array}$ & Serving size \\
\hline Glucose-monohydrate & $91.0 \mathrm{~g} / 100 \mathrm{~g}$ & $27.5 \mathrm{~g}$ dissolved in $250 \mathrm{ml}$ water \\
Strawberry \& Banana smoothie & $11.7 \mathrm{~g} / 100 \mathrm{ml}$ & $213.7 \mathrm{ml}$ \\
Mango \& Passion Fruit smoothie & $10.6 \mathrm{~g} / 100 \mathrm{ml}$ & $235.8 \mathrm{ml}$ \\
\hline
\end{tabular}


Table 2. Plant cell sizes of the smoothies and whole fruit (Mean $\pm \mathrm{SD})$.

\begin{tabular}{ccccccc}
\hline & \multicolumn{2}{c}{ Smoothies } & \multicolumn{3}{c}{ Fruit } \\
& Mango \& & Strawberry \& & Mango & Passion & Strawberry & Banana \\
& Passion fruit & Banana & & fruit & & \\
\hline Length $(\mu \mathrm{m})$ & $175.9 \pm 89.4$ & $226.3 \pm 118.0$ & $81.4 \pm 19.9$ & $47.9 \pm 25.2$ & $147.3 \pm 45.9$ & $131.3 \pm 37.1$ \\
Width $(\mu \mathrm{m})$ & $74.4 \pm 33.0$ & $130.8 \pm 80.7$ & $57.9 \pm 17.1$ & $29.2 \pm 13.9$ & $81.5 \pm 50.4$ & $76.4 \pm 28.0$ \\
\hline
\end{tabular}


Table 3. Subject characteristics.

\begin{tabular}{lc}
\hline Characteristic & $n=10$ \\
\hline Age $($ years $)$ & $26.6 \pm 7.4$ \\
Height $(\mathrm{m})$ & $1.7 \pm 0.1$ \\
Weight $(\mathrm{kg})$ & $66.1 \pm 7.1$ \\
BMI $\left(\mathrm{kg} / \mathrm{m}^{2}\right)$ & $20.6 \pm 7.6$ \\
Fat mass $(\%)$ & $22.5 \pm 8.9$ \\
Lean body mass $(\mathrm{kg})$ & $50.9 \pm 7.1$ \\
\hline
\end{tabular}


Table 4. GI value, GL value (per $250 \mathrm{ml}$ bottle) and classification of the smoothies.

\begin{tabular}{lcccc}
\hline & $\begin{array}{c}\text { GI value } \\
(\text { mean } \pm \text { SEM) }\end{array}$ & Classification & $\begin{array}{c}\text { GL value } \\
(\text { mean } \pm \text { SEM })\end{array}$ & Classification \\
\hline Strawberry \& Banana smoothie & $39 \pm 4$ & Low & $11.4 \pm 1.3$ & Medium \\
Mango \& Passion Fruit smoothie & $36 \pm 5$ & Low & $9.7 \pm 1.2$ & Low \\
\hline
\end{tabular}




\section{Figures}
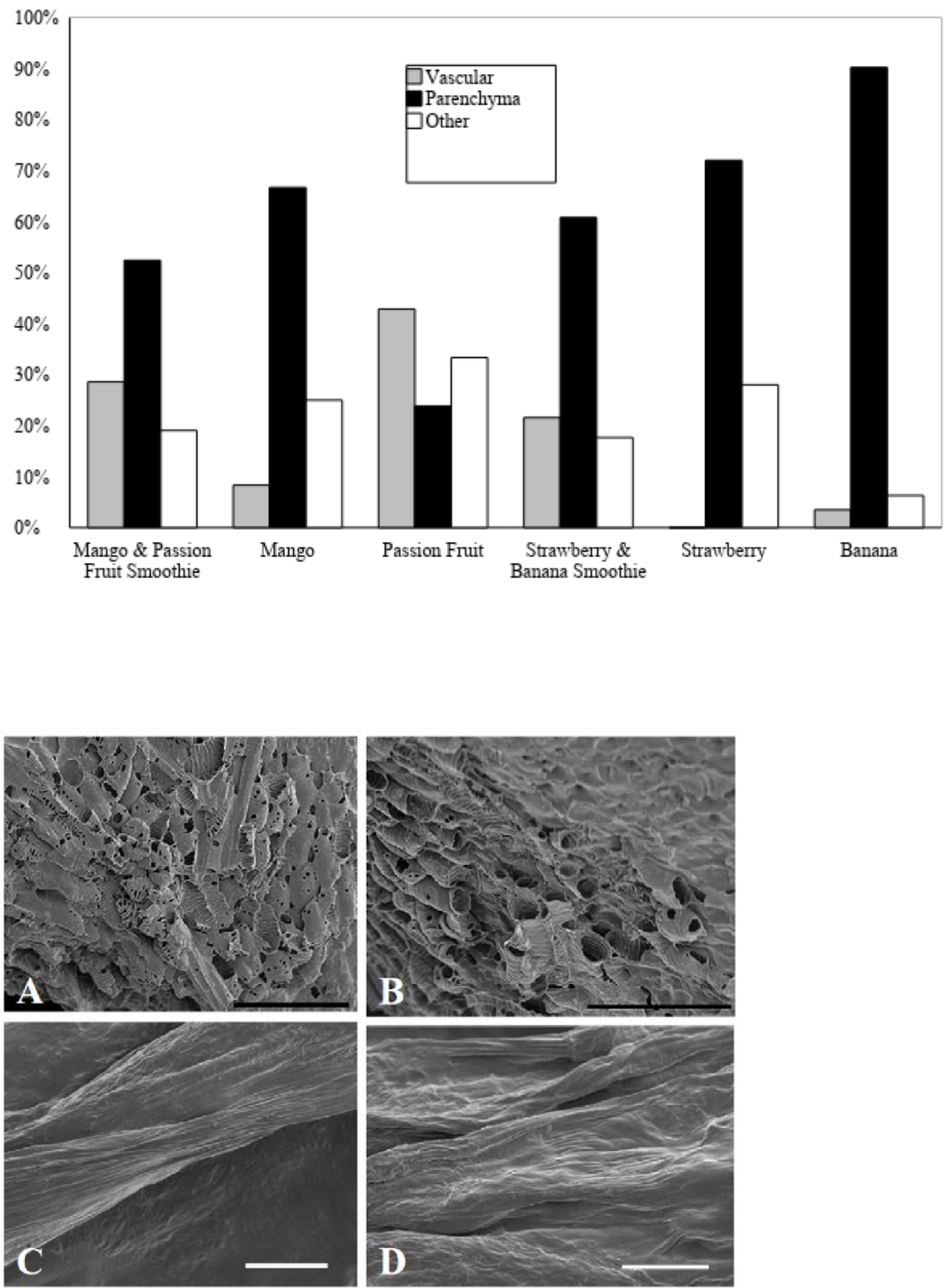


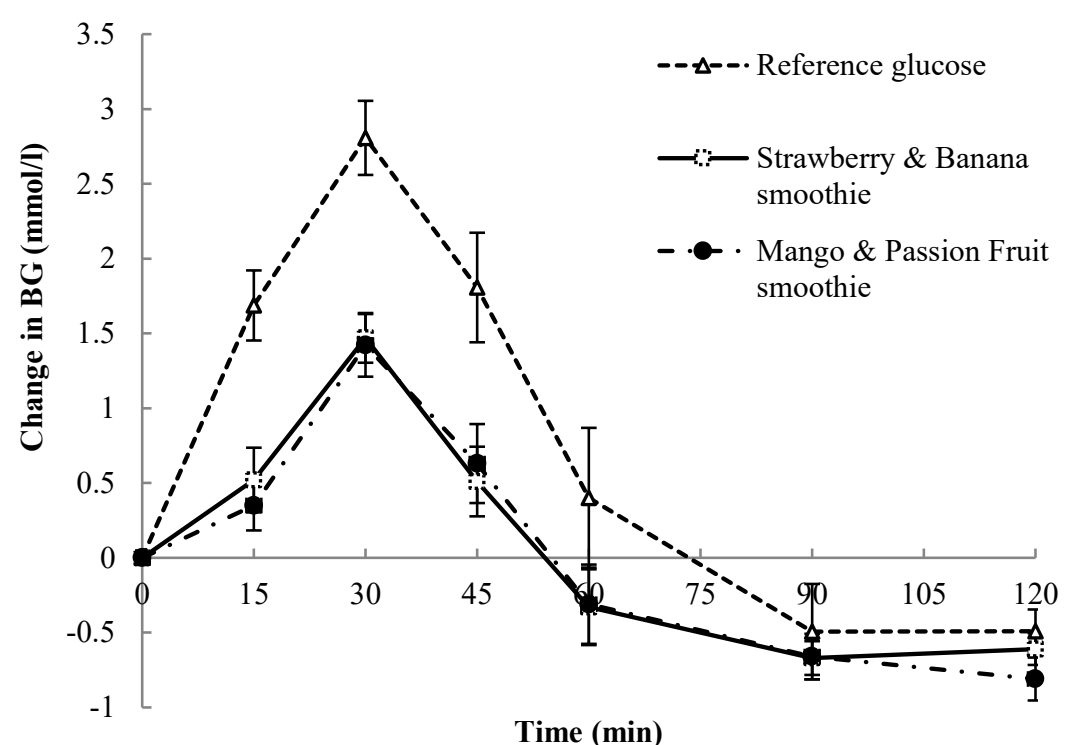

Figures Captions

Figure 1. Percentage of distinct cell types observed in smoothie and fruit samples.

Figure 2. Scanning electron micrographs demonstrating the presence of vascular tissue in the smoothie. Bars $=50$ microns $($ A\&B: Strawberry \& Banana Smoothie; C\&D: Mango \& Passionfruit Smoothie).

Figure 3. Mean (SEM) change in BG (mmol/l) over time of the reference glucose, Strawberry \& banana smoothie and the Mango $\&$ Passion Fruit smoothie. 